\title{
Avaliação microscópica de amostras comerciais de café
}

\author{
Nadinne Medeiros Assis ${ }^{1}$, Carlos Alexandre Marques ${ }^{1 *}$, Michelle Costa da Silva $^{1}$
}

Neste trabalho objetivou-se avaliar a qualidade de amostras comerciais de café, através da caracterização microscópica e detecção gravimétrica de possíveis sujidades e adulterantes. As amostras comerciais de café, pertencentes a quatro marcas distintas, foram adquiridas comercialmente e analisadas em triplicatas. Neste estudo, as análises microscópicas realizaram-se usando microscópio estereoscópico e fotônico, seguindo-se a metodologia usual. Também se realizaram análises por microscopia eletrônica de varredura (MEV) com detecção de elementos químicos por dispersão de raio-X (EDS) acoplado. A quantificação de cascas e paus foi feita por análise gravimétrica, seguindo-se a metodologia da Fundação Ezequiel Dias (MG). Em todas as marcas identificaram-se fragmentos vegetais indesejáveis, como cascas e paus do próprio cafeeiro e sujidades consideradas sem risco à saúde humana. $\mathrm{Na}$ análise gravimétrica, quantificaram-se fragmentos de cascas e paus do próprio cafeeiro em três das quatro marcas analisadas. $\mathrm{Na}$ análise por MEV/EDS para identificação da presença de possíveis fragmentos metálicos, as quatro marcas apresentaram a presença principalmente de partículas de ferro, além de outros metais em menor proporção. Conclui-se, assim, que todas as marcas apresentaram inconformidades quanto à presença de adulterantes, segundo o programa do selo ABIC, entretanto, estão em conformidade com a legislação vigente por não apresentarem risco à saúde humana.

Palavras-chave: Café; qualidade; adulterações; microscopia alimentar.

\section{Microscopic evaluation of coffee commercial samples}

This paper aimed to evaluate the quality of some commercial coffee samples, through microscopic characterization and gravimetric detection of possible dirtiness and adulterants. Commercial coffee samples, belonging to four distinct brands, were purchased commercially and analyzed in triplicates. In this study, microscopic analyzes were performed using a stereoscopic and photonic microscope, following the usual methodology. Analyzes by scanning electron microscopy (SEM) with detection of chemical elements by X-ray dispersion (EDS) coupled were also performed. The quantification of barks and pieces of sticks was made by gravimetric analysis, following the methodology of the Ezequiel Dias Foundation (MG). In all brands, undesirable vegetable fragments were identified, such as coffee tree peels and sticks and dirt considered to be without risk to human health. In the gravimetric analysis, fragments of coffee trees were quantified in three of the four brands analyzed. In the SEM/EDS analysis to identify the presence of possible metal fragments, the four brands showed the presence mainly of iron particles, in addition to other metals in a smaller proportion. It is concluded, therefore, that all brands presented non-conformities regarding the presence of adulterants, according to the ABIC program, however, they are in compliance with the current legislation because they do not present a risk to human health.

Keywords: Coffee; quality; adulterations; food microscopy.

\footnotetext{
${ }^{1}$ Instituto Federal de Educação, Ciência e Tecnologia do Rio de Janeiro (IFRJ), Campus Nilópolis, RJ. Endereço para Correspondência: R. Cel. Délio Menezes Porto, 1045, Centro, Nilópolis, RJ. CEP: 26.530-060.*E-mail: carlos.alexandre@ifrj.edu.br.
} 


\section{INTRODUÇÃO}

Coffea é um gênero que pertence à família Rubiaceae e cujas espécies podem variar de tamanho entre dois a cinco metros de altura na fase adulta. Atualmente, o gênero possui 103 espécies de onde se colhem as sementes que são denominadas popularmente como café. Através destas sementes, tem-se a preparação de uma bebida saborosa e estimulante conhecida pelo mesmo nome. No Brasil, Coffea arabica (café arábica) e Coffea canephora (café conillon ou robusta) são as espécies mais cultivadas. O primeiro produz cafés de mais finos e requintados, considerados de melhor qualidade, enquanto o outro é caracterizado por um trato mais rude, possuindo uma acidez mais baixa e teor de cafeína maior do que no arábica, sendo muito utilizado na produção de cafés solúveis, devido à maior quantidade de sólidos solúveis ${ }^{[1]}$.

Durante o processo de torrefação ocorrem reações que produzem substâncias químicas cuja combinação define o sabor e o aroma que a bebida proporcionará. Nessa combinação são gerados complexos resultantes da presença de vários componentes químicos voláteis e não voláteis. Dentre estes compostos, 29 já foram identificados como os principais responsáveis pelo aroma característico do café torrado e moído[2,3]. A união das propriedades físicas do grão, cru e torrado, com as propriedades sensoriais da bebida pode definir a qualidade do café. Contudo, fatores distintos vêm interferindo na qualidade dos produtos consumidos pela população. Isso é decorrente da interação entre os fatores edafoclimáticos, as condições de cultivo, a conduta e o manejo da lavoura, além das fases do processo do café comercializado, cru e torrado. Essas fases são a colheita, o processamento, a secagem, o armazenamento, torrefação, beneficiamento e moagem ${ }^{[4,5]}$.

As impurezas encontradas nos cafés são oriundas das fases de processamento para obtenção do café torrado e moído[1]. O material estranho inserido no produto, acaba levando a uma alteração na sua qualidade e acarretando diferentes danos ao consumidor, sejam de ordem econômica ou até mesmo à sua saúde. É comum a inserção de outras matérias-primas de custo inferior, dessa forma, as principais fraudes encontradas no café torrado e moído são: cacau (Theobroma cacao) - restos do pericarpo e da semente; milho (Zea mays) - fragmentos da cariopse seca, arroz (Oryza sativa) cariopse seca; feijão (Phaseolus vulgaris) - semente; soja (Glycine max) - fragmentos de semente; açaí (Euterpe oleracea) - fragmentos da semente torrada, açúcar (sacarose, através da adição direta na forma de pedaços de "caramelo"), cevada (Hordeum vulgare) e triguilho (Triticum sp.) - espiguilhas fragmentadas. O cacau é adicionado com a intenção de melhorar o sabor. A soja e o feijão torrados e moídos transmitem gosto forte ao produto. $\mathrm{O}$ caramelo de açúcar para o aumento de coloração. $O$ restante é mais utilizado para o aumento de volume e peso ${ }^{[6,7]}$.

Antes da torrefação do café, este pode ser fraudado mediante a adição de matérias estranhas, como milho e cevada. A aparência granulosa do café, a cor característica e a textura oleosa e aderente colaboram para que substâncias e materiais estranhos tornem-se quase imperceptíveis, dificultando o reconhecimento sem o auxílio específico de métodos analíticos e aparelhos adequados ${ }^{[8]}$.

Com a finalidade de mudar esse quadro e melhorar a qualidade do café, tanto para os consumidores internos quanto aos externos e, até mesmo para aumento das exportações, diversos órgãos regulamentadores e fiscalizadores criaram requisitos, limitações e condições para a melhoria da qualidade do café distribuído nacionalmente e internacionalmente.

Em 1989, a ABIC (Associação Brasileira da Indústria de Café) ${ }^{[9]}$ instituiu o Programa de Controle do Café Torrado e Moído/Selo de Pureza ABIC com o objetivo de "devolver ao consumidor a credibilidade no produto, desenvolver, em todo o público, conhecimentos sobre o café, retornar ao consumo per capita de café no Brasil dos anos 60 e solucionar o problema de fraudes". No regulamento são preconizadas infrações e suas respectivas penalidades para viso do selo, sendo mais importante ressaltar o it 2 m 8.9.1 que estabelece que sejam proibidos elementos estranhos ao café, sendo citado da seguinte maneira:

A mistura de elementos estranhos ao café tais como milho, açúcar, centeio, cevada, soja, entre outros é considerada infração gravíssima e a penalidade correspondente é o 
cancelamento ao uso do "Selo de Pureza ABIC", previsto na letra "d" do item 8.1 .

Um estudo que foi realizado por Miya e Shirose[10] apud. Vegro[11] consistiu em submeter cafés fraudados com cascas e paus, pergaminho e resíduos de celulose a degustadores e foi concluído que:

$$
\begin{aligned}
& \text { Para alterar } \\
& \text { significativamente o aroma } \\
& \text { e a acidez do café padrão de } \\
& \text { bebida mole, são } \\
& \text { necessários } 20 \% \text { de cascas, } \\
& 30 \% \text { de resíduos celulósicos } \\
& \text { e } 50 \% \text { de pergaminhos. E } \\
& \text { para alterar } \\
& \text { significativamente o aroma } \\
& \text { e a acidez do café-padrão de } \\
& \text { bebida dura, são necessários } \\
& 40 \% \text { de cascas e de resíduos } \\
& \text { celulósicos e } 50 \% \text { de } \\
& \text { pergaminhos. }
\end{aligned}
$$

Já a ANVISA, Agência Nacional de Vigilância Sanitária, adota a Resolução da Diretoria Colegiada - RDC no 14, de 28 de março de 2014 com o objetivo de "avaliar a presença de matérias estranhas macroscópicas e microscópicas, indicativas de riscos a saúde humana e/ou as indicativas de falhas na aplicação das boas práticas na cadeia produtiva de alimentos e bebidas, e fixar seus limites de tolerância”. Ou seja, esta RDC tem aplicação aos alimentos destinados ao consumo humano[12].

Em relação ao café, a RDC 14/2014 preconiza como tolerância para café torrado e moído, o limite máximo de 60 fragmentos de insetos que indiquem falhas das boas práticas quando estes não são considerados indício de risco em $25 \mathrm{~g}$ do produto, sendo indicada como a metodologia analítica "café torrado e moído 988.16 b (16.02.02)" - da AOAC International (Association of Official Analytical Chemists) ${ }^{[12] .}$

Já o Ministério da Agricultura, Pecuária e Abastecimento do Brasil (MAPA), através da Instrução Normativa no 16, de 24 de maio de 2010 estabeleceu um Regulamento Técnico para o Café Torrado em Grão e Café Torrado e Moído, definindo requisitos de identidade e qualidade. Esta instrução normativa preconizava que o percentual máximo permitido de impurezas, sedimentos e matérias estranhas era de $1 \%$. As matérias estranhas, isoladamente, deveriam corresponder a, no máximo, $0,1 \%$, sendo a "película prateada" que se desprende da torra do café não seria considerada impureza ${ }^{[13]}$. Contudo, essa Instrução Normativa (IN) foi revogada pela IN no 7, de 22 de fevereiro de 2013[14].

Baseando-se nas informações supra-citadas, o presente trabalho se propõe a observar, verificar e caracterizar amostras comerciais de café, à luz da microscopia fotônica e eletrônica de varredura, observando-se aspectos relacionados aos danos na embalagem, a autenticidade e pureza da matériaprima (café), além da presença de matérias estranhas macro e microscópicas (sujidades).

\section{METODOLOGIA}

\section{Amostragem e Caracterização das Amostras}

Foram analisadas quatro marcas distintas de café, três delas de menor expressão (em relação à quantidade de vendas) que foram comparadas à marca líder de mercado (marca $\mathrm{C}$ ). Três delas são detentoras do selo de pureza da ABIC (marcas A, C e D) e uma delas (marca B), não possui tal selo. As amostras das marcas A, C e D são comercializadas em toda a região metropolitana do estado do Rio de Janeiro. A marca B foi obtida em Muriaé (MG) e não é comercializado no estado do Rio de Janeiro. As amostras de café foram adquiridas comercialmente e analisadas em três repetições, sendo todas pertencentes a lotes distintos.

Os procedimentos analíticos foram realizados em amostras de café torrado e moído em suas embalagens originais, lacradas em embalagens de $250 \mathrm{~g}$ ou $500 \mathrm{~g}$. Todos os procedimentos descritos na literatura estão relatados nas etapas subsequentes.

\section{Homogeneização da Amostra Através do Método de Quarteamento}

As amostras foram pesadas $(250 \mathrm{~g}) \mathrm{e}$ posteriormente colocadas em um tabuleiro, dispersas e bem homogeneizadas com auxílio de espátula. Posteriormente, foram quarteadas. Para isso, foram divididas em quatro partes iguais $\mathrm{e}$ então, dois quadrantes foram retirados. Os 
quadrantes opostos restantes foram novamente misturados. Esse processo foi repetido até que se obtivesse $50 \mathrm{~g}$ de amostra homogeneizada ${ }^{[12]}$.

\section{Processo de Desengorduramento da Amostra}

O processo de desengorduramento, feito após o quarteamento, consistiu em retirar $2 \mathrm{~g}$ da amostra, usando-se uma balança semi-analítica da marca RadWag, modelo WTB 2000. O restante da amostra seguiu o procedimento descrito no item sobre análise de matérias estranhas.

A amostra pesada foi dispersa levemente, com cuidado para que não rompesse a tensão superficial, sob a superfície de $60 \mathrm{~mL}$ de clorofórmio, colocado em um béquer, em capela de exaustão. Em seguida revolveu-se, vagarosamente, a camada do pó de café com um bastão de vidro e verificou-se a formação de precipitação de sedimento. No caso de precipitação, seguiu-se a metodologia descrita por Lopez ${ }^{[15]}$ Após observação, agitou-se com um bastão de vidro o conteúdo do béquer, que foi deixado em repouso por 20 minutos.

A seguir, em um papel qualitativo, foi realizada uma filtração e recolheu-se o filtrado em um erlenmeyer de $250 \mathrm{~mL}$, deixando-se o resíduo numa capela de exaustão para secagem. O conteúdo do papel de filtro, do bastão e o pó de café aderido na parede do béquer foram transferidos para um tamis de 60 mesh. Logo após, executou-se o processo de tamisação com auxílio de pincel no 16 , até que não se perceba a passagem do pó, ao bater o tamis sobre uma superfície branca e limpa. Em uma placa de Petri, dispôs-se o resíduo retido no tamis para avaliação ao estereomicroscópio quanto à presença de matérias estranhas, quantificando-se as impurezas (cascas e paus), se necessário ${ }^{[6,15]}$.

\section{Quantificação de cascas e paus}

Para este procedimento, seguiu-se a metodologia de Lopez ${ }^{[15]}$. Usando uma placa de Petri, pesou-se todo o resíduo retido no tamis (observando-se, em seguida, ao estereomicroscópio), em balança analítica da marca Shimadzu, modelo UniBloc AUY220 e anotou-se o valor $R$. Deste resíduo $R$, pesou-se $0,1 \mathrm{~g}$ ou $0,2 \mathrm{~g}$ em balança analítica, a mesma usada anteriormente, usando-se outra placa de Petri e anotando-se o valor $(P)$. Então, dispôs-se uma gota de água destilada sobre uma lâmina de vidro. Com o auxílio de um estilete umedecido e estereomicroscópio, separou-se todas as cascas e paus do resíduo, transferindo-as para a lâmina com água. Em seguida, foi feita a transferência para um pesa-filtro com tampa, anteriormente aquecido por 1 hora em estufa a $105^{\circ} \mathrm{C}\left( \pm 5^{\circ} \mathrm{C}\right)$ e pesado (Pfv). Após resfriamento em dessecador, pesaram-se as cascas e paus da lâmina. Logo após, o pesa-filtro semi-aberto foi levado à estufa a $105^{\circ} \mathrm{C}\left( \pm 5^{\circ} \mathrm{C}\right)$ por uma hora. Retirou-se com auxílio de uma pinça adequada, o pesa filtro tampado, resfriou em dessecador por 30 minutos. O processo se repetiu até peso constante (Pfc), procedendo-se conforme cálculo da equação 1 a seguir.

$$
P t c=P f c-P f v \frac{(P t c x R x 50)}{P}=X \% \text { cascasepaus }
$$

Equação 1 - Cálculo de cascas e paus

Onde:

Pfc $=$ Peso do pesa filtro + cascas e paus

$\mathrm{Pfv}=$ Peso do pesa filtro vazio

Ptc $=$ Peso total de cascas e paus

$\mathrm{P}=$ Peso do resíduo para catação $(0,1 \mathrm{a} 0,2 \mathrm{~g})$

$\mathrm{R}=$ Peso do resíduo retido no tamis

\section{Análise de Matérias Estranhas Identificação de material vegetal}

As análises microscópicas foram feitas usando-se microscópio estereoscópico, modelo Edutec 505, marca Astral Científica, com aumentos de 20x e 40x e por microscópio fotônico com câmera digital e ocular micrométrica acopladas, modelo ABM103, marca Alltion, aumentos de 40x, 100x, 400x e 1000x, seguindo-se as metodologias descritas pelo Instituto Adolfo Lutz[7]. Refere-se a um método de isolamento de materiais vegetais não oriundos do cafeeiro, como grãos e sementes de outras espécies. Essas matérias, consideradas estranhas às amostras, se encontram muitas vezes moídas e torradas junto com o café, portanto, a identificação do material ao microscópio óptico leva em conta considerar as alterações ocorridas nos tecidos vegetais após tratamento físico, térmico e químico.

Após detecção de matéria estranha, seja de origem vegetal ou não, foi realizado o procedimento a seguir: 
- Com o auxílio do estereomicroscópio, estilete e/ou pinças retirou-se amostras do material estranho da placa contendo o restante da amostra de café.

- Dispôs-se o material retirado em lâminas e analisou-se ao microscópio óptico, identificando-se os elementos histológicos, pesquisando e identificando-se as matérias estranhas. Para facilitar na identificação, foi utilizado, para comparação, livros, artigos científicos $[6,7,15,16,17,18,19]$, bancos de imagens e fotografias do próprio laboratório de Microscopia.

- Foram montadas lâminas desses materiais utilizando água destilada ou água glicerinada $50 \%$. Se necessário, foram preparadas lâminas utilizando lugol ou utilizando luz polarizada para auxiliar na identificação de amidos.

\section{Identificação de fragmentos metálicos}

Para investigar a presença de fragmentos metálicos foram feitas análises utilizando-se $\mathrm{O}$ Microscópio Eletrônico de Varredura (MEV) Phenom World, modelo Pro-X, com porta-amostra redutor de carga, no laboratório de Microscopia do campus Nilópolis do IFRJ. Fragmentos encontrados foram aderidos aos suportes metálicos com 12,7 $\mathrm{mm}$ de diâmetro (stubs de alumínio), da marca Ted Pella Inc., com fita adesiva e introduzidos no suporte próprio que, por sua vez, foi acoplado ao aparelho para posterior observação. Devido às características do aparelho e conforme recomendações do fabricante, não são necessárias as etapas de ponto crítico e metalização. Após serem encontrados fragmentos metálicos, procedeu-se a microanálise de elementos por dispersão de raio-X (EDS) acoplado ao MEV, a fim de detectar a natureza química desses elementos [20]. Todos os resultados obtidos nos diferentes tipos de microscópios foram registrados através de fotomicrografias.
Para essa análise, foram pesados $50 \mathrm{~g}$ de cada amostra e colocada cada uma em um béquer, em seguida completou-se o volume de 1L e colocaram um agitador magnético (peixinho). Logo após, os béqueres foram deixados sob agitação por 15 minutos em placas de agitação da marca Thelga, modelo TMA 10 CF. Em seguida, os agitadores magnéticos foram retirados e observados a microscópico esteoroscópico para a identificação de possíveis metais. Observando a presença de fragmentos metálicos, o procedimento seguiu para a análise no módulo EDS (Energy-dispersive X-ray Spectroscopy) do Microscópio Eletrônico de Varredura (MEV) Phenom World Pro-X do laboratório de microscopia do IFRJ campus Nilópolis, configurando-se o canhão de elétrons na potência de $15 \mathrm{kV}$ (point).

\section{RESULTADOS E DISCUSSÃO}

\section{Análise de matérias estranhas e registro dos resultados}

Em laboratório foram analisadas amostras de quatro marcas distintas (A, B, C e D), todas em triplicata. Ou seja, na primeira marca (A) foram obtidas três amostras de $500 \mathrm{~g}$ cada e, nas outras três marcas (B, C e D), foram obtidas três amostras disponíveis em embalagens de $250 \mathrm{~g}$ cada. Todas as marcas foram aprovadas quanto à quantidade do produto descrito na embalagem (peso), à autenticidade da matéria-prima, evidenciada pela presença significativa de fragmentos da semente do café que servem como caracteres diagnósticos (Figura 1), além do prazo de validade. A marca C continha uma amostra com peso abaixo do descrito na embalagem. Nessas embalagens, por sua vez, não foi constatado nenhum tipo de avaria, exceto na marca D, onde se encontraram 36 furos irregularmente dispostos, expondo o produto a uma potencial contaminação. 
Figura 1 - Fibras da testa da semente que comprovam a autenticidade da matéria-prima. Legenda: A - fibras da testa da semente em detalhe (aumento 400x). B - detalhe das pontoações oblíquas (seta) das fibras (aumento 1000x).

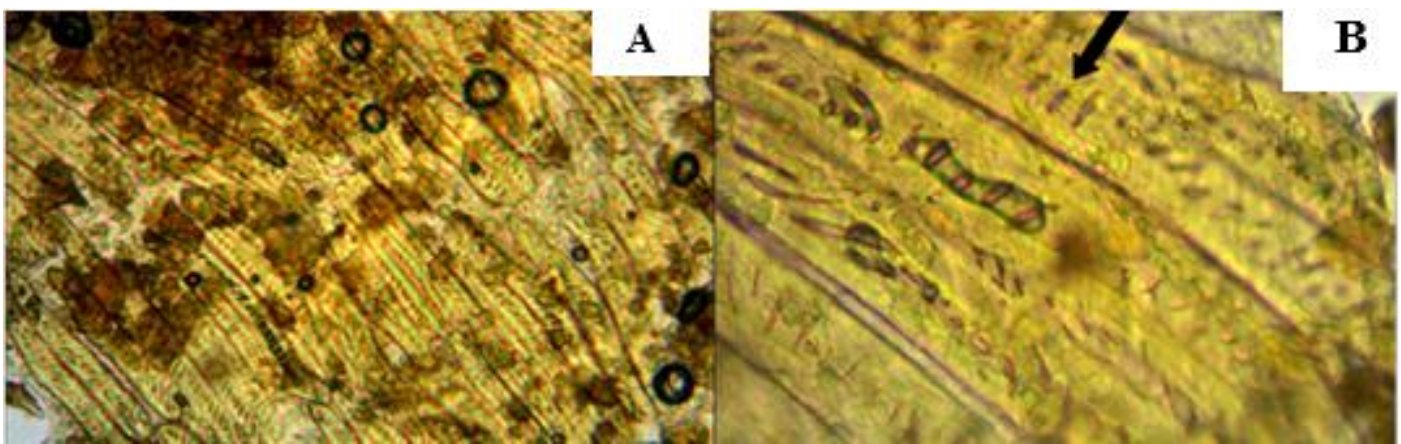

Fonte: elaboração própria.

$\mathrm{Na}$ marca A foram encontrados e identificados fragmentos de milho, cacau, arroz, caramelo de açúcar, soja, fragmentos de cascas e paus do próprio cafeeiro, além de dois pêlos humanos e um pequeno agrupamento de hifas de um fungo. Já na marca B, identificou-se milho, cacau, arroz, caramelo de açúcar, cascas e paus e um pêlo humano. Enquanto que na marca $C$, foi identificado arroz, cacau e cascas e paus do próprio café, todos em pequena quantidade, além de um pêlo humano. $\mathrm{Na}$ marca $\mathrm{D}$, encontraram-se arroz, cacau, milho, muitas cascas e paus do próprio café, um inseto, duas antenas de mosquito (fragmentos de insetos), dois pêlos humanos e duas hifas (Figura 2). A tabela abaixo (Tabela 1) reúne todos os resultados obtidos para as amostras analisadas:

Figura 2 - Fragmentos vegetais encontrados nos cafés analisados. Os elementos circulados mostram um exemplo de cada tipo de sujidade encontrada. Legenda: A - milho (aumento 40x). B - arroz (aumento 40x). C - arroz (aumento 40x). D - soja (aumento 40x). E - cacau (aumento 40x). F caramelo de açúcar (aumento 40x). G - cascas e paus do café (aumento 40x).

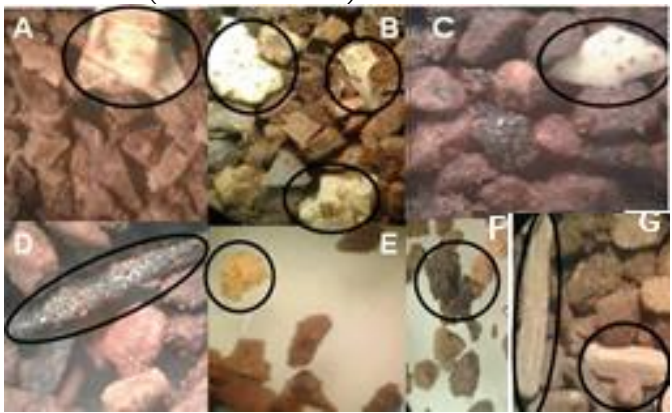

Fonte: elaboração própria.
Tabela 1 - Resultados da detecção de sujidades nas etapas feitas com tamisação após desengorduramento e apenas com tamisação.

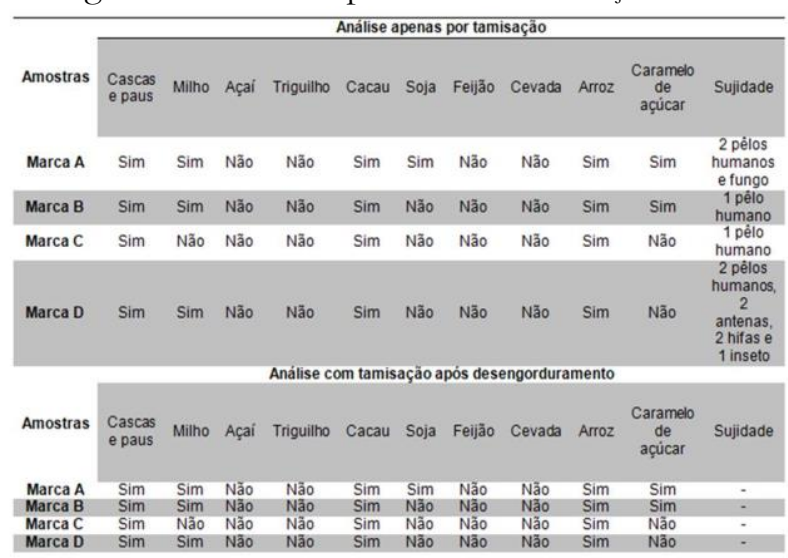

Fonte: Elaboração própria

Conforme previamente mencionado, a presença desses materiais estranhos pode alterar a qualidade do café, principalmente no que se diz respeito às características sensoriais (odor e sabor), além do que, pode significar risco à saúde, dependendo da sujidade encontrada. Os pêlos humanos encontrados evidenciam as falhas que se referem às boas práticas de fabricação. Já a presença de fungos pode ter sido causada por diferentes fatores, como alta umidade no local de armazenamento, por exemplo. A presença de hifas de fungos indica a necessidade de realizar um estudo microbiológico, a fim de identificar a espécie, quando possível. As antenas de mosquito e o inseto também indicam falhas nas boas práticas de fabricação. As sujidades encontradas (Figura 3) não representam um risco alto à saúde ou na qualidade 
sensorial da bebida a ser produzida, até porque foram encontradas em pequenas quantidades que são toleradas, segundo a RDC no 14 , de 28 de março de 2014 da ANVISA.

Figura 3 - Sujidades encontradas nas amostras comerciais de café. Legenda: A1 - pêlo humano em detalhe (aumento 400x). A2 - pêlo humano encontrado na marca A (aumento 100x). B1 Fragmento de inseto em detalhe (aumento 400X). B2 - Fragmento de inseto (antena) encontrado na marca D (aumento 100X).

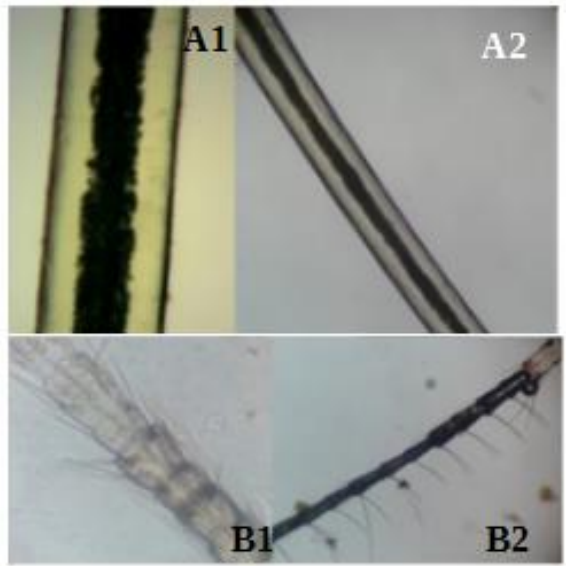

Fonte: elaboração própria.

A quantidade de fragmentos vegetais encontrados (Figura 1) nas marcas A, B e D pode interferir nas características sensoriais do produto. Foi observado, por exemplo, que na marca $\mathrm{D}$ havia um notável odor amadeirado no produto, mascarando o aroma natural do café, possivelmente caracterizado devido à grande quantidade de cascas e paus. Na marca $\mathrm{C}$, a quantidade de cascas e outros fragmentos caulinares do café, bem como dos fragmentos vegetais adulterantes eram muito pequenas. Nas marcas $\mathrm{A}$ e $\mathrm{B}$, apesar de não se perceber odor amadeirado, foi sentido um odor ligeiramente mais doce que os demais, possivelmente advindo do caramelo de açúcar, que traz também a finalidade de escurecer a coloração da bebida, no momento em que o café está sendo coado. Os outros fragmentos vegetais, em todas as marcas cujas quantidades eram mais numerosos e foram possivelmente acrescidos no intuito de objetivo de aumentar volume e peso do produto. Essa suspeita motivou a realização de um estudo de determinação quantitativa (gravimetria), apresentado adiante.
Os fragmentos de cascas e paus do próprio café, além de milho, soja, centeio, triguilho, cevada, arroz, entre outros fragmentos vegetais são relatados na literatura como impurezas encontradas frequentemente no café torrado e moído brasileiro[21-24]. Em 1999, o Instituto Adolfo Lutz avaliou em diversas cidades brasileiras, 1854 amostras de café e constatou que 354 amostras continham impurezas ou adulterações como estas comumente encontradas, já em 2010, uma nova análise realizada verificou que cerca de $40 \%$ das amostras continham alguma adulteração ou impureza. Enquanto a ABIC, numa pesquisa realizada em 2008 identificou fraudes em 583 de 2400 marcas de café torrado e moído, cerca de 25\% das amostras [25,26].

Teixeira et al.[22], através da análise microscópica, observaram em todas as 14 marcas comerciais de café torrado e moído analisadas, a presença de fragmentos estranhos, porém em proporções diferentes com predomínio de cascas e paus. Esse resultado corrobora com o presente trabalho. As cascas e paus, segundo Assad et al.[24] são consideradas impurezas oriundas do processamento do café, que podem não ser adicionadas intencionalmente, entretanto, isso muda de cenário quando se encontra uma alta concentração desses fragmentos, supondo-se que tenha sido feito intencionalmente [24], no intuito de agregar peso ao produto final. Estes autores[24] também relataram que a presença dos fragmentos vegetais são mais difíceis de serem detectados devido a sua forma e coloração, podendo ser mascarados no café torrado e moído, pois estes fragmentos também sofrem o processo de torrefação. No presente trabalho, a análise microscópica permitiu detectar outros fragmentos vegetais.

Entre os vários métodos encontrados, a análise microscópica é um processo convencional bem utilizado. Entretanto, o problema encontrado se dá nos métodos analíticos empregados, pois estes são processos lentos, dependentes da análise visual, usando-se microscópios, onde as impurezas são identificadas ${ }^{24,27]}$ e que também dependem da experiência do analista. Também é importante a comparação com imagens disponíveis na literatura especializada. Todas essas dificuldades relatadas explicam os diferentes resultados encontrados em trabalhos distintos. 
A fraude no café é uma prática antiga e ilícita empregada em diversos lugares ao redor do mundo. Assim como em todos os países cafeicultores, no Brasil o problema de fraude traz uma constante preocupação aos seus órgãos fiscalizadores ${ }^{[28]}$. Segundo parâmetros estabelecidos pela RDC 14/2014, todas as marcas estariam em conformidade, ou seja, dentro dos limites máximos tolerados de matérias estranhas. Vale lembrar que o limite máximo tolerado, atualmente, é de 60 fragmentos de insetos que indiquem falhas das boas práticas, mesmo quando estes não são considerados "indício de risco" em $25 \mathrm{~g}$ do produto analisado. Além da presença dos materiais vegetais, observouse a presença de um aglomerado, posteriormente identificado como amido de arroz.

Em relação ao selo da ABIC, trata-se de um programa de controle de participação não obrigatória, desenvolvida no intuito de devolver e manter a credibilidade junto ao consumidor, sendo possuidora de um regulamento em que não se permitem elementos estranhos ao café. Assim sendo, todas as marcas estariam fora de conformidade, inclusive a líder de mercado (marca C). Vale lembrar que, das quatro marcas analisadas, três eram detentoras de tal selo, com destaque para as marcas $\mathrm{A}$ e $\mathrm{D}$, que o possuem selo, mesmo tendo sido encontradas consideráveis quantidades de elementos estranhos (Tabela 2).

Foi realizada uma contagem manual de fragmentos estranhos encontrados nas amostras analisadas. Essa contagem foi realizada com 0,5-1,0 $\mathrm{g}$ de cada material, através da separação por meio de peneiras granulométricas (tamis) em sequência (16, 20, 32 e 60 mesh). O resultado dessa contagem pode ser visto na tabela a seguir (Tabela 2):
Tabela 2 - Contagem Manual de Fragmentos nos Cafés Comerciais.

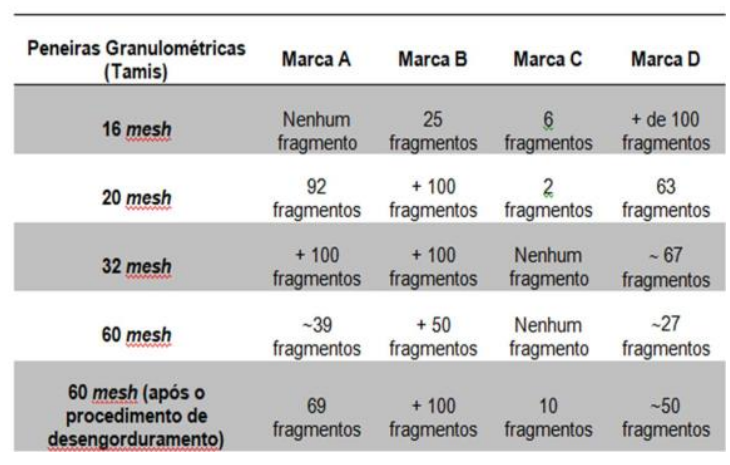

Fonte: Elaboração própria

A contagem realizada apresentou resultados consideráveis, destacando a diferença marcante da quantidade de fragmentos encontrados entre cada tamis. É possível perceber que as marcas A, B e D possuem maior quantidade de fragmentos isolados, totalizando aproximadamente mais de 300 fragmentos para A, mais de 375 para B e mais de $240 \mathrm{em} \mathrm{D}$, enquanto em $\mathrm{C}$, foram isolados apenas 18 fragmentos.

Os elementos separados e contabilizados são fragmentos de origem vegetal, como mencionado anteriormente, cascas e paus (fragmentos de caule) dos próprios cafeeiros. Os valores encontrados não chegam a afetar qualidade do café segundo Miya e Shirose[10] apud. Vegro[11]. Segundo os autores, somente proporções a partir de $30 \%$ desses resíduos celulósicos e 50\% de pergaminho (endocarpo papiráceo e tecidos fibrosos), alteram o aroma e a acidez do café. Porém, integram o peso total das amostras.

Em vista disso, ganha importância a realização de estudos relacionados à análise sensorial em cafés como ferramenta de avaliação da qualidade desse produto.

\section{Análise de fragmentos metálicos}

Obtiveram-se resultados positivos para a presença de fragmentos metálicos em todas as marcas analisadas. Nas amostras da marca A identificou-se a presença do elemento ferro (Fe); na marca $\mathrm{B}$, havia elementos de Fe e silício (Si); já na marca $\mathrm{C}$, havia a presença de $\mathrm{Fe}$, zinco $(\mathrm{Zn})$, alumínio (Al) e Si e já para a marca $\mathrm{D}$, detectou-se $\mathrm{Fe}, \mathrm{Zn}, \mathrm{Na}$ e $\mathrm{Cl}$. Os resultados das análises 
realizadas com o MEV/EDS estão compilados nas

figuras a seguir (Figura 4):

Figura 4 - Análises de MEV/EDS realizados em amostras das marcas A (4A), B (4B), C (4C e 4D) e D (4E).
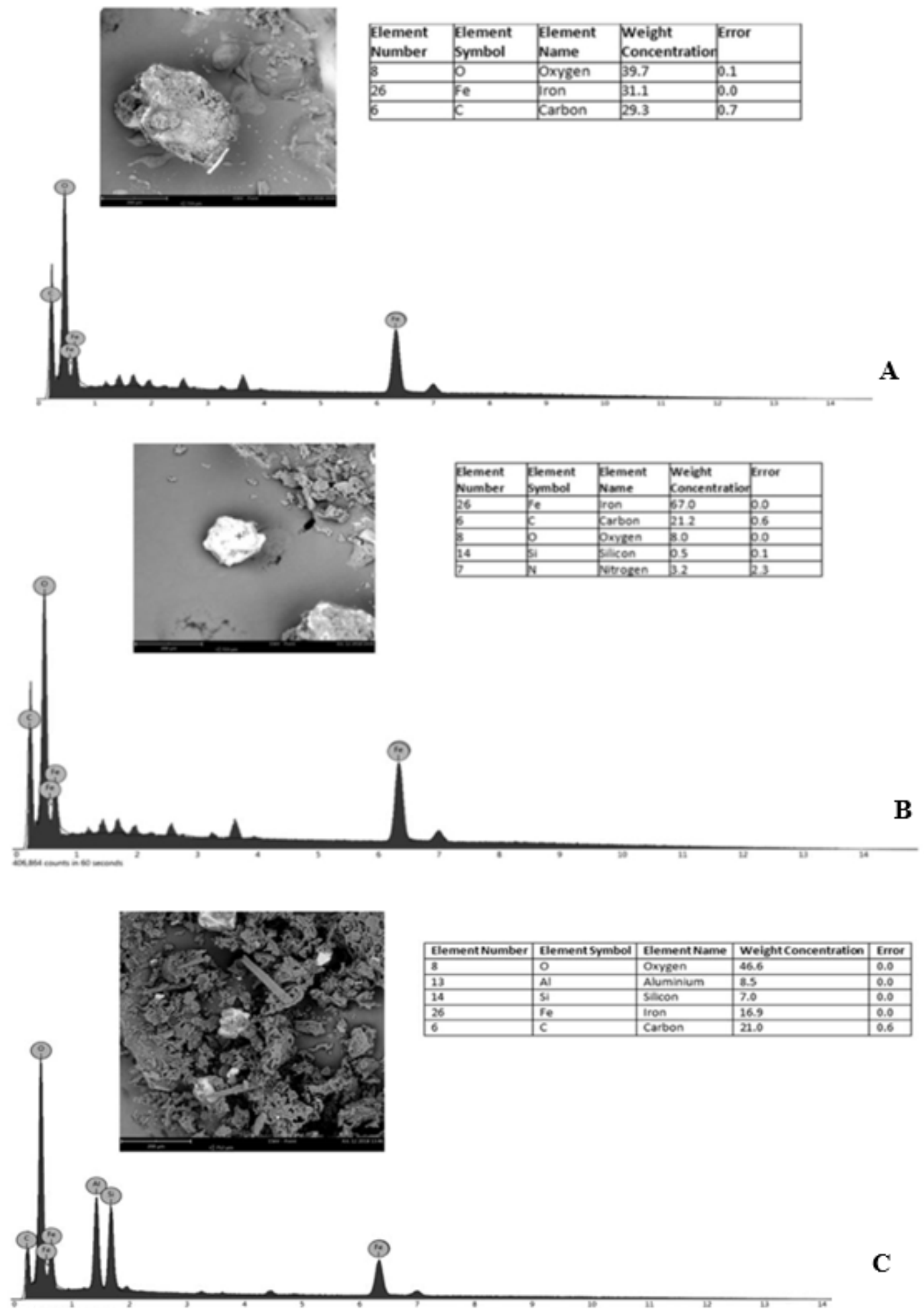


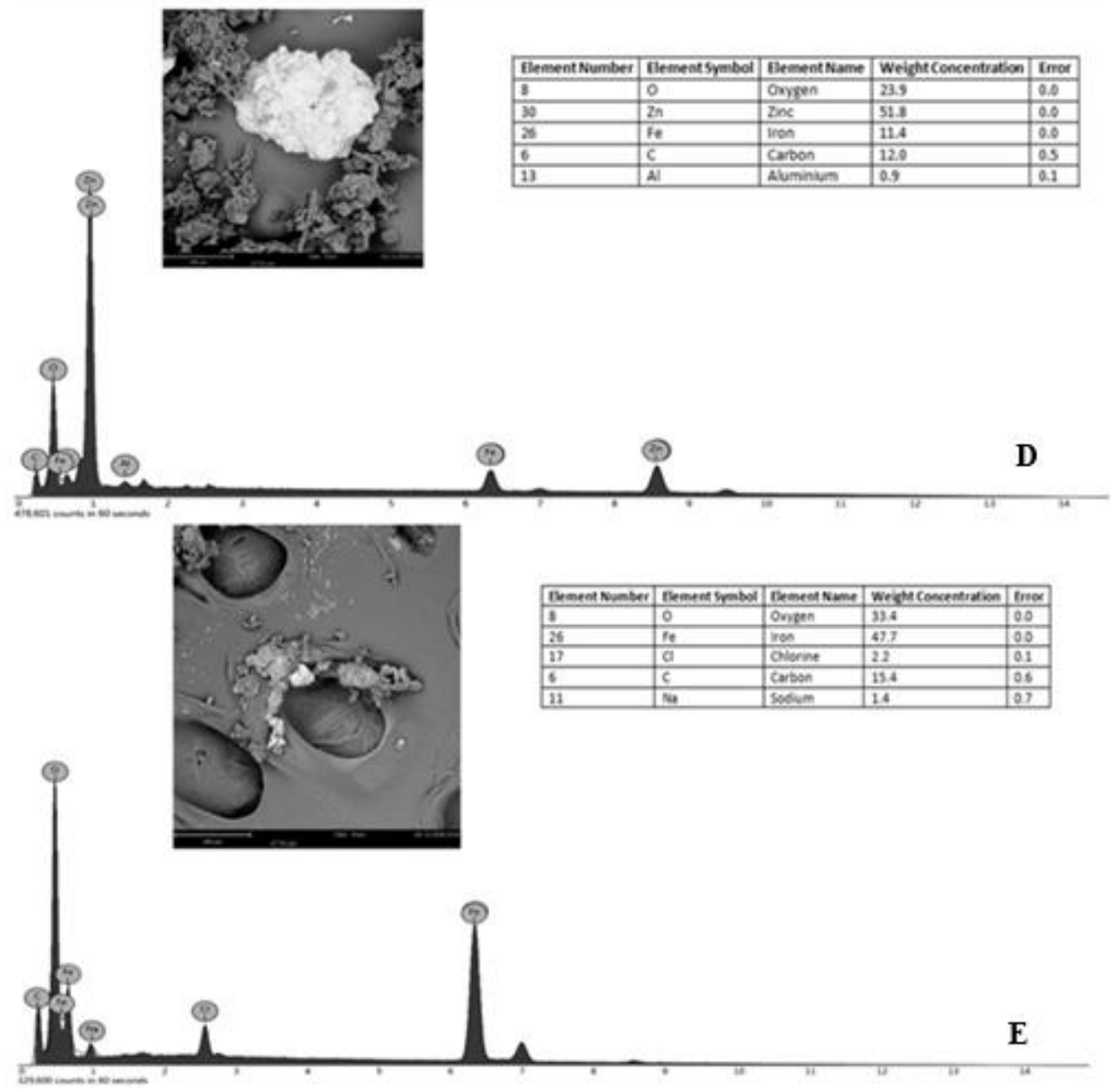

Fonte: Elaboração própria. 
Todos esses elementos encontrados são provenientes, provavelmente, dos processos de secagem, moagem ou beneficiamento, durante $\mathrm{O}$ processo de produção do café comercial. A presença de limalha de ferro nas amostras pode ser explicada pela perda de pequenos fragmentos nos moinhos metálicos. Já a sílica, indica a provável presença de grãos de areia ou pode ainda compor solos argilosos, que comumente são formados por silicatos de alumínio. Solos argilosos podem conter uma grande variedade de elementos químicos o que explicaria os resultados do EDS.

\section{Determinação quantitativa de cascas e paus}

Para quantificação de cascas e paus seguiram-se os procedimentos já descritos, após a etapa de desengorduramento da amostra, calculando-se seu valor através a equação 1. Para tal determinação foram utilizadas as mesmas amostras, também em três repetições.

A partir dos dados obtidos foi possível perceber que, na marca $A$, não havia quantidade significativa à ser mensurada (só foram separados três fragmentos de cascas e paus). Já a para as outras marcas foi possível realizar o cálculo, tendo-se obtido o resultado de $1,02 \%$ de cascas e paus em $0,2035 \mathrm{~g}(P)$, na marca B. Para a marca C, encontraram-se $0,34 \%$ de cascas e paus em $0,2018 \mathrm{~g}$ $(P)$ e para a marca $\mathrm{D}, 0,52 \%$ de cascas e paus em $0,2019 \mathrm{~g}(P)$.

A ABIC, em seu programa de controle para o selo de pureza, considera infração gravíssima a presença de elementos estranhos, como cascas e paus e demais fragmentos vegetais, estranhos às amostras, e penaliza o fabricante com o cancelamento do uso do selo. Já a RDC 14/2014 da ANVISA não proíbe ou estabelece limite para a presença destes adulterantes. Vale lembrar que, para haver alteração significativa no aroma e na acidez da bebida mole, é necessária a presença de $20 \%$ de cascas e, para a bebida dura, $40 \%$ de cascas, segundo Miya e Shirose [10] apud. Vegro[11].

\section{Observação de sedimentos}

Seguindo-se o procedimento já descrito por Lopez ${ }^{[15]}$, não houve precipitação de nenhum sedimento em nenhuma amostra

\section{CONCLUSÃO}

A elaboração do presente trabalho possibilitou a obtenção de dados relevantes, a saber:

- As amostras analisadas de três marcas distintas (A, B e D) mostraram a presença de sujidades mas, principalmente, de adulterantes que representam inconformidades segundo as normas da ABIC. A marca $C$, apesar de não estar isenta de adulterantes e de sujidades leves, apresentou resultados muito mais satisfatórios.

- Verificou-se que os adulterantes encontrados podem influenciar na qualidade do produto, sendo imprescindíveis os estudos de microscopia e de gravimetria para avaliação desses parâmetros.

\section{AGRADECIMENTOS}

Ao CNPq pela bolsa PIBITI e ao IFRJ pela verba PROCIÊNCIA de pesquisa.

\section{REFERÊNCIAS}

[1] Oliveira IP de, Oliveira LC, Moura CSF de. Cultura de café: Histórico, Classificação Botânica e Fases de Crescimento. Rev. Fac. Montes Belos. 2012; 5(4):17-32.

[2] Melo WLB. A Importância da Informação Sobre do Grau de Torra do Café e Sua Influência nas Características Organolépticas da Bebida. Comunicado Técnico Embrapa 58 [Internet]. São Carlos, 2004;1-4. Disponível em: https://ainfo.cnptia.embrapa.br/digital/bitstream/CNP DIA/10452/1/CT58_2004.pdf. Acesso em 27 out 2017.

[3] Sarrazin C, Le Quéré JL, Gretsch C, Liardon R. Representativeness of coffee aroma extracts: A comparison of different extraction methods. Food Chem. 
2000;70(1):99-106.

[4] Camargo MB, Salva TJG. Influência do Clima na Produtividade de Grãos e na Qualidade da Bebida do Café. In: Cafés Qual Asp tecnológicos, científicos e Comer. Campinas, 2007;324-30.

[5]Vitorino MD, Franca AS, Oliveira LS, Andrade FM. Variação de características físicas e químicas de café arábica durante a torra parte II: características químicas. II Simp. Pesq. dos cafés do Bras [Internet]. 2001;1596604. Acesso em 27 out 2017.

[6]. Fontes EAF, Fontes PR. Microscopia de Alimentos: Fundamentos Teóricos. Viçosa: Ed. UFV; 2005.

[7] Matos EC, Matozinhos FCL, Sampaio ME, Valenzuelo VCT, Moreira WA, Costa CR, Nascimento RP do. Atlas de Microscopia: Café torrado e Moído (Coffea sp). Fundação Ezequiel Dias (FUNED). 2012

[8] INMETRO. Café Torrado e Moído [Internet]. 2017. Disponível em: http://www.inmetro.gov.br/consumidor/produtos/cafe. asp. Acesso em 28 out 2017.

[9] Associação Brasileira da Indústria de Café (ABIC. Regulamento do Programa Permanente de Controle da Pureza do Café [Internet]. 2017. Disponível em: http://abic.com.br/certificacao/pureza/regulamento.

Acesso em 28 out 2017.

[10] Miya EE, Shirose I. Fraudes de café e influência na qualidade da bebida. Bol do Inst Tecnol Aliment. 1977;49:123-49.

[11] Vegro CLR. Programa de autofiscalização da ABIC: a trajetória do selo de pureza do café. Informações Econômicas. 1993;23(12):31-39.

[12] BRASIL. Ministério da Saúde, Secretaria de Vigilância Sanitária. Resolução RDC no 14, de 28 de março de 2014 [Internet]. Dispõe sobre "Matérias Estranhas Macroscópicas e Microscópicas em Alimentos e Bebidas", seus limites de tolerância e dá outras providências. Diário Oficial da União no 61, Brasília, 31 mar. 2014. ANVISA - Agência Nacional de Vigilância Sanitária. Disponível em: http://portal.anvisa.gov.br/legislacao\#/visualizar/2918.

[13] BRASIL. Ministério da Agricultura, Pecuária e Abastecimento do Brasil. Instrução Normativa no 16 de 24 de maio de 2010. "Estabelece o Regulamento Técnico para o Café Torradoem Grão e Café Torrado e Moído, definindo o seu padrão oficialde classificação, com os requisitos de identidade e qualidade, a amostragem, o modo de apresentação e a marcação ou rotulagem na formados Anexos à presente Instrução Normativa." [nternet]. Diário Oficial da União no 98, Brasília, 24 mai 2010. Ministério da Agricultura, Pecuária e Abastecimento do Brasil. Disponível em: https://normas.gov.br/materia/Lasset publisher/NebW5rLVWyej/content/id/3557468 0. Acesso em 05 jun 2020.

[14] BRASIL. Ministério da Agricultura, Pecuária e Abastecimento do Brasil. Instrução Normativa no 7, de 22 de fevereiro de 2013. Revoga a Instrução Normativa no 16 de 24 de maio de 2010. Diário Oficial da União 37, Seção 1, pág. 7, de 25 fev. 2013 Disponível em: http://www.lex.com.br/legis 24209045 INSTRUCAO NORMATIVA N 7 DE 22 DE FEVEREIRO DE 2013.aspx. Acesso em 05 jun 2020.

[15] Lopez FC. Determinação do sedimento, cascas e paus no café torrado e moído. Rev Inst Adolfo Lutz [nternet]. São Paulo, 1974;34:29-34. Disponível em: http://www.ial.sp.gov.br/resources/insituto-adolfolutz/publicacoes/rial/70/rial_341-2_1974/e396.pdf.

Acesso em 20 out 2017.

[16] Boese JL; Cichowicz SM. AOAC Official Method. Extraneus Materials: Isolation. 16 ed. 1995.

[17] Menezes-Júnior JBF. Fraudes do café. Revista do Instituto Adolfo Lutz. 1952;1: 111-144.

[18] Vasquez AW. Hairs (Chapter 9). FDA Tech Bull. 1981;1:125-51.

[19] Menezes-Junior JSF. Investigações sobre o exame microscópico de algumas substâncias alimentícias. Rev Inst Adolfo Lutz. 1949;9:18-77.

[20] Nascimento AM. Caracterização morfoanatômica, cromatografia em camada delgada e testes fitoquímicos em amostras comerciais de Ziziphus joazeiro Mart. (Rhamnaceae) (Trabalho de Conclusão do curso). Nilópolis: Instituto Federal de Educação, Ciência e Tecnologia do Rio de Janeiro; 2015.

[21] Amboni RDMC, Francisco A, Teixeira E. Utilização de microscopia eletrônica de varredura para detecção de fraudes em café torrado e moído. Ciência e Tecnologia de Alimentos. 1999;19(3):311-313.

[22] Teixeira OR, Passos FR, Mendes FQ. Qualidade físico-química e microscópica de 14 marcas comerciais de café torrado e moído. Coffee Science. 2016;11(3):395402.

[23] Licciardi R, Pereira R, Gualberto FA, Mendonça LMVL, Furtado EF. Avaliação físico-química de cafés torrados e moídos do sul de Minas Gerais [Internet]. Ciênc. Tecnol. Aliment. 2005;25(3):425-429. Disponível em https://www.scielo.br/pdf/cta/v25n3/27006.pdf 
[24] Assad ED, Sano EE, Cunha SAR da, Correa TBS, Rodrigues HR. Identificação de impurezas e misturas em pó de café por meio de comportamento espectral e análise de imagens digitais. Pesquisa Agropecuária Brasileira. 2002; 37(2):[21]1-[21]6.

[25] Associação Brasileira da Indústria de Café (ABIC). Programa permanente de controle da pureza do café 2005 [Internet]. 2005. Disponível em: http://www.abic.com.br. Acesso em 05 jun 2020.

[26] Fagioli M. Que café nós bebemos. Interural Revista do Agronegócio. 2010;38(8):24-25.

[27] Cunha SAR, Assad ED, Sano EE. Fraudes em Café Torrado e Moído: Quantificação através do SpringCafé. In: Anais do X SBSR, Foz do Iguaçu, PR; 21-26 abril 2001, INPE, p. 35-40.

[28] REIS N. Detecção de adulteração de café torrado e moído com cascas de café e Milho por espectroscopia no infravermelho (dissertação). Belo Horizonte: UFMG; 2012. 